\title{
Evaluation of Antibacterial Activity of Iron Oxide Nanoparticles Against Escherichia coli
}

\author{
Mehrdad Khatami ${ }^{1,2}$, Mohammad Reza Aflatoonian ${ }^{3 *}$, Hakim Azizi ${ }^{4 *}$, Farideh Mosazade ${ }^{1}$, Ahmad Hoshmand ${ }^{1}$, \\ Marcos Augusto Lima Nobre ${ }^{5}$, Farzad Minab Poodineh ${ }^{4}$, Mansour Khatami ${ }^{3}$, Sam Khraazi ${ }^{1}$, Hadi Mirzaeei ${ }^{6}$ \\ ${ }^{1}$ Nano Bioelectrochemistry Research Center, Bam University of Medical Sciences, Bam, Iran \\ ${ }^{2}$ Nanomedicine and Nanobiology Research Center, Shiraz University of Medical Sciences, Shiraz, Iran \\ ${ }^{3}$ Research Center for Tropical and Infectious Diseases, Kerman University of Medical Sciences, Kerman, Iran \\ ${ }^{4}$ Research Center for Tropical and Infectious Diseases, Zabol University of Medical Sciences, Zabol, Iran \\ ${ }^{5}$ Fac de Ciências e Tecnologia-FCT, Universidade Estadual Paulista-UNESP, Presidente Prudente-SP, 19060-900, Brazil \\ ${ }^{6}$ School of Medicine, Zabol University of Medical Sciences, Zabol, Iran
}

\section{*Correspondence to \\ Mohammad Reza Aflatoonian, \\ Email: mraflatoonian@gmail.com; \\ Hakim Azizi, \\ Tel: +983433257316 \\ Fax: +983433257543 \\ Email: hakimazizi190@yahoo.com}

Received August 10, 2017

Accepted October 10, 2017

Published online December 31, 2017

\begin{abstract}
Introduction: Considering the usefulness of metal oxide nanoparticles in biology and biomedicine, iron oxide nanoparticles were biosynthesized using bioresource engineering to evaluate its antibacterial activity against Escherichia coli.

Methods: Macrodilution method was used for calculating the lowest concentration which prevented the growth of bacteria (minimum inhibitory concentration $[\mathrm{MIC}]$ ), and the lowest concentration that destroyed all bacterial cells (minimum bactericidal concentration $[\mathrm{MBC}]$ ). Results: The lowest concentration of iron oxide nanoparticles that inhibited the growth of $E$. coli (MIC) was recorded at $250 \mu \mathrm{g} / \mathrm{mL}$. On the other hand, the MBC of iron oxide nanoparticles was calculated at $500 \mu \mathrm{g} / \mathrm{mL}$.

Conclusion: Iron oxide nanoparticles were produced by a green and eco-friendly, simple and inexpensive method. The results showed the inhibitory effect of iron oxide nanoparticles on $E$. coli at $250 \mu \mathrm{g} / \mathrm{mL}$. This may suggest using these nanoparticles as potential antibacterial agents. Keywords: Minimum inhibitory concentration, Minimum bactericidal concentration, Iron oxide nanoparticles, Antibacterial, Macrodilution, Escherichia coli
\end{abstract}

Please cite this article as follows: Khatami $M$, Aflatoonian MR, Hakim Azizi $\mathrm{H}$, et al. Evaluation of antibacterial activity of iron oxide nanoparticles against Escherichia coli. Int J Basic Sci Med. 2017;2(4):166169. doi:10.15171/ ijbms.2017.31.

\section{Introduction}

Antimicrobial agents considerably help to prevent and treat infectious diseases in humans and animals; however, the increase of resistant microbial strains has turned to a serious challenge in medicine. ${ }^{1-4}$ Nanomaterials have attracted the researchers' interest due to their significant antibacterial activity. ${ }^{5,6}$ In recent years, antimicrobial nanoparticles have paved the way for medicine and biotechnology. ${ }^{7,8}$ Nanoparticles with high antimicrobial activity are a new class of biomedical materials. ${ }^{9-13}$

Iron oxide nanoparticles have a high specific surface area, so they are able to interact with bacterial surface structures. Furthermore, because of their relatively small size, they can facilitate the particle uptake by bacterial cells. The iron oxide nanoparticles are produced through various physicochemical methods. ${ }^{14-17}$ The chemical approaches may be harmful for human and impose environmental and health risks. In another approach, magnetic nanoparticles are produced by biological resources (biosynthesis or green synthesis). Here, we aimed to evaluate the antibacterial impacts of iron oxide nanoparticles on a common bacterial strain in clinical practice. $^{18,19}$

\section{Methods}

The iron oxide nanoparticles were synthesized using bioresource engineering as previously described. ${ }^{3}$ Briefly, Rosmarinus officinalis leaves $(20 \mathrm{~g})$ were washed, dried and powdered. The obtained powder was added to the glass flask containing $2000 \mathrm{~mL}$ sterile water. The final mixture was heated

Copyright (c) 2017 The Author(s); Published by Zabol University of Medical Sciences. This is an open-access article distributed under the terms of the Creative Commons Attribution License (http://creativecommons.org/licenses/by/4.0), which permits unrestricted use, distribution, and reproduction in any medium, provided the original work is properly cited. 
at $80^{\circ} \mathrm{C}$ for 30 minutes. The sample was centrifuged. All steps were carried out under sterile condition (laminar air-flow). The $\mathrm{FeCl}_{3} \cdot 6 \mathrm{H}_{2} \mathrm{O}, 98 \%$ (ferric (III) chloride hexahydrate) stock solution $(0.1 \mathrm{M})$ was prepared. Twenty mililiters of obtained extract was mixed with $1 \mathrm{mM}$ of $\mathrm{FeCl}_{3}$ solution under constant stirring. The color change from light yellow to black indicated the production of iron oxide nanoparticles. ${ }^{20}$

\section{Antibacterial Test}

Bacterial strain used in this study (Escherichia coli, 1330) was supplied from Microbial Collection of Iranian Science and Technology Organization, with the Persian Type Culture Collection (PTCC). First, for the bacterial strain, the cell suspension with $0.5 \mathrm{McFarland}$ turbidity $\left(10^{8} \times 1.5\right)$ was prepared and each well of the ELISA plate was filled with $100 \mathrm{~mL}$ of Muller-Hinton broth (MHB) and then $100 \mathrm{~mL}$ of iron oxide nanoparticles was poured in the first cast well; Afterward, $100 \mu \mathrm{L}$ of this mixture was removed and transferred to the next well. This process continued to the last well. Finally, the concentrations of iron oxide nanoparticles (2000, 1000, 500, 250 and 125 $\mu \mathrm{g} / \mathrm{mL})$ were obtained. ${ }^{21}$

Minimum Inhibitory Concentration and Minimum Bactericidal Concentration Determination

The control sample (positive control) only contained 100 $\mu \mathrm{L}$ of bacteria with cell culture medium that reflected the growth of the bacteria in the absence of iron oxide nanoparticles. After dilution of bacterial strains, the final suspension was incubated for 24 hours at $37^{\circ} \mathrm{C}$. Afterward, the growth of bacterial strains was determined by visual observation. The concentration of nanoparticles that prevented the growth of bacteria was recognized as minimum inhibitory concentration (MIC) and the lowest concentration that destroyed all bacterial cells was considered as minimum bactericidal concentration $(\mathrm{MBC}) .^{22}$

\section{Results}

Transmission electron microscopy (TEM) images of biosynthesized iron oxide nanoparticles are shown in Figure 1 ; the particle size range was from 1 to $12 \mathrm{~nm}$. The iron oxide nanoparticles were mainly spherical and approximately monodisperse.

The study of antimicrobial effects of iron oxide nanoparticles using macrodilution method and the calculation of MIC and MBC against E. coli were performed. The antibacterial activity of iron oxide nanoparticles was investigated at concentrations of 2000, $1000,500,250$ and $125 \mu \mathrm{g} / \mathrm{mL}$. The lowest concentration of iron oxide nanoparticles that inhibited the growth of $E$. coli (MIC) was observed at $250 \mu \mathrm{g} / \mathrm{mL}$, while the MBC of iron oxide nanoparticles against $E$. coli was calculated at $500 \mu \mathrm{g} / \mathrm{mL}$.

\section{Discussion}

Initially, we eco-friendly synthesized iron oxide nanoparticles. These nanoparticles have small size and good stability when natural resources are used. In biosynthetic production of iron oxide nanoparticles, in comparison with physicochemical methods, less time is needed.

The findings showed that biogenic iron oxide nanoparticles represent antibacterial activity against $E$. coli in a dosedependent manner. Thukkaram et $\mathrm{al}^{23}$ reported that the highest inhibition of iron oxide nanoparticles $(29 \mathrm{~mm})$ against Staphylococcus aureus was observed at $150 \mathrm{ug} /$ $\mathrm{mL}$. Masadeh et $\mathrm{al}^{24}$ reported MIC value of iron oxide nanoparticles against Enterobacter aerogenes, Proteus mirabilis, and Klebsiella pneumoniae in the range of 10-320 $\mu \mathrm{g} / \mathrm{mL}$ of iron oxide nanoparticles. In the present study, $\mathrm{MIC}$ and $\mathrm{MBC}$ of iron oxide nanoparticles against $E$. coli was obtained at $250 \mu \mathrm{g} / \mathrm{mL}$ and $500 \mu \mathrm{g} / \mathrm{mL}$, respectively. The mechanisms of antibacterial activity of these agents are not well known; however, there may be a role for these agents to act as membrane permeability enhancers, or as disruptors of the cell wall by generating reactive oxygen species. $^{25}$

These results were obtained in vitro, but it should be mentioned that the high antibacterial effects of the studied iron oxide nanoparticles are not selective, and it can be generally effective on all kinds of human cells.

The application of iron oxide nanoparticles in pharmaceutical fields dates back to the beginning of the 1970s. Iron oxide nanoparticles have also been used for drug targeting, magnetic resonance imaging, ${ }^{3}$ as spoilers for magnetic spectroscopy, and more recently as sensors for biomolecules.

The use of iron oxide nanoparticles as antibacterial agents has also been reported. ${ }^{26}$ Engineering designs, physiochemical characteristics, biomedical applications, toxicity and magnetic nanotoxicology of iron oxide nanoparticles have been discussed. ${ }^{27}$ In this study, we explored the antibacterial activity of iron oxide nanoparticles against a common bacterial strain.

\section{Conclusion}

Iron oxide nanoparticles were synthesized by a green
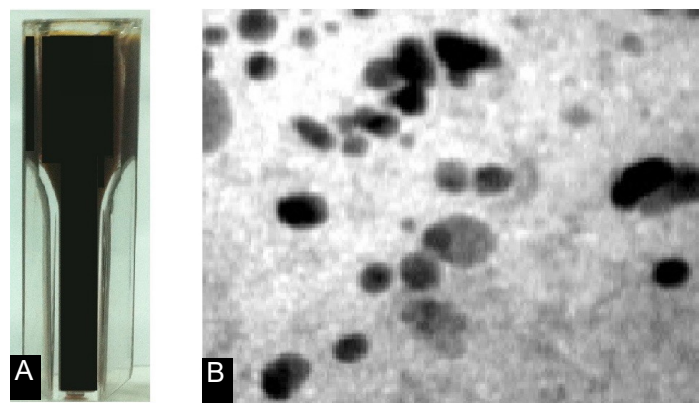

Figure 1. (A) Iron Oxide Nanoparticles Solution. (B) TEM Images of Iron Oxide Nanoparticles 
and eco-friendly, simple and inexpensive method. The nanoparticles showed dose-dependent toxicity against $E$. coli growth. The iron oxide nanoparticles can be used as alternative antibacterial agents.

\section{Ethical Approval}

The study protocol was approved by Ethics Committee of Bam University of Medical Sciences, Bam, Iran.

\section{Competing Interests}

Authors declare that they have no potential conflict of interests.

\section{Acknowledgement}

The study was financially supported by Bam University of Medical Sciences, Bam, Iran (grant No. 95/4).

\section{References}

1. Ventola CL. The antibiotic resistance crisis: part 1: causes and threats. P T. 2015;40(4):277-283.

2. Zare E, Pourseyedi S, Khatami M, Darezereshki E. Simple biosynthesis of zinc oxide nanoparticles using nature's source, and it's in vitro bio-activity. Journal of Molecular Structure. 2017;1146:96-103. doi: 10.1016/j. molstruc.2017.05.118

3. Khatami M, Alijani H, Sharifi I, et al. Leishmanicidal Activity of Biogenic Fe3O4 Nanoparticles. Sci Pharm. 2017;85(4):36.

4. Khatami M, Mehnipor R, Poor MHS, Jouzani GS. Facile Biosynthesis of silver nanoparticles using Descurainia sophia and evaluation of their antibacterial and antifungal properties. Journal of Cluster Science. 2016;27(5):16011612. doi:10.1007/s10876-016-1028-5

5. Mahmoud W, Elazzazy AM, Danial EN. In vitro evaluation of antioxidant, biochemical and antimicrobial properties of biosynthesized silver nanoparticles against multidrugresistant bacterial pathogens. Biotechnol Biotechnol Equip. 2017;31(2):373-379. doi:10.1080/13102818.2017.1282836

6. Hameed ASH, Karthikeyan C, Ahamed AP, et al. In vitro antibacterial activity of $\mathrm{ZnO}$ and $\mathrm{Nd}$ doped $\mathrm{ZnO}$ nanoparticles against ESBL producing Escherichia coli and Klebsiella pneumoniae. Sci Rep. 2016;6:24312. doi:10.1038/srep24312

7. Khatami M, Heli H, Jahani PM, Azizi H, Nobre MAL. Copper/copper oxide nanoparticles synthesis using Stachys lavandulifolia and its antibacterial activity. IET Nanobiotechnology. 2017;11(6):709-713.

8. Sharifi F, Sharififar F, Sharifi I, Alijani H, Khatami M. Cytotoxicity, leishmanicidal, and antioxidant activity of biosynthesized zinc sulfide nanoparticles using Phoenix dactylifera. IET Nanobiotechnology. 2017. doi:10.1049/ iet-nbt.2017.0204

9. Nasrollahzadeh $M$, Atarod M, Sajadi SM. Green synthesis of the $\mathrm{Cu} / \mathrm{Fe} 3 \mathrm{O} 4$ nanoparticles using Morinda morindoides leaf aqueous extract: A highly efficient magnetically separable catalyst for the reduction of organic dyes in aqueous medium at room temperature. Applied Surface Science. 2016;364:636-644.

10. Lunge S, Singh S, Sinha A. Magnetic iron oxide (Fe3O4) nanoparticles from tea waste for arsenic removal. J
Magn Magn Mater. 2014;356:21-31. doi: 10.1016/j. jmmm.2013.12.008

11. Niroomand S, Khorasani-Motlagh $M$, Noroozifar $M$, Jahani S, Moodi A. Photochemical and DFT studies on DNA-binding ability and antibacterial activity of lanthanum(III)-phenanthroline complex. J Mol Struct. 2017;1130:940-950. doi: 10.1016/j.molstruc.2016.10.076

12. Jahani S, Khorasani-Motlagh M, Noroozifar M. DNA interaction of europium(III) complex containing 2,2'-bipyridine and its antimicrobial activity. J Biomol Struct Dyn. 2016;34(3):612-624. doi:10.1080/07391102.2 015.104848

13. Moghaddam HM, Beitollahi H, Tajik S, Jahani S, Khabazzadeh H, Alizadeh R. Voltammetric determination of droxidopa in the presence of carbidopa using a nanostructured base electrochemical sensor. Russian Journal of Electrochemistry. 2017;53(5):452-460. doi:10.1134/s1023193517050123

14. Hufschmid R, Arami H, Ferguson RM, et al. Synthesis of phase-pure and monodisperse iron oxide nanoparticles by thermal decomposition. Nanoscale. 2015;7(25):1114211154. doi:10.1039/c5nr01651g

15. Glasgow W, Fellows B, Qi B, et al. Continuous synthesis of iron oxide $(\mathrm{Fe} 3 \mathrm{O} 4)$ nanoparticles via thermal decomposition. Particuology. 2016;26:47-53. doi: 10.1016/j.partic.2015.09.011

16. Pulit J, Banach M, Kowalski Z. Chemical Reduction as the main method for obtaining nanosilver. J Comput Theor Nanosci. 2013;10(2):276-284. doi:10.1166/jctn.2013.2691

17. Zaimy MA, Saffarzadeh N, Mohammadi A, et al. New methods in the diagnosis of cancer and gene therapy of cancer based on nanoparticles. Cancer Gene Ther. 2017;24(6):233-243. doi:10.1038/cgt.2017.16

18. Khorrami MB, Sadeghnia HR, Pasdar A, GhayourMobarhan M, Riahi-Zanjani B, Darroudi M. Role of pullulan in preparation of ceria nanoparticles and investigation of their biological activities. J Mol Struct. 2018;1157:127-131. doi: 10.1016/j.molstruc.2017.12.053

19. Charbgoo F, Ahmad MB, Darroudi M. Cerium oxide nanoparticles: green synthesis and biological applications. Int J Nanomed. 2017;12:1401-1413. doi:10.2147/IJN. S124855

20. Groiss S, Selvaraj R, Varadavenkatesan T, Vinayagam R. Structural characterization, antibacterial and catalytic effect of iron oxide nanoparticles synthesised using the leaf extract of Cynometra ramiflora. $J \mathrm{Mol}$ Struct. 2017;1128(Suppl C):572-578. doi: 10.1016/j. molstruc.2016.09.031

21. Bano F, Baber M, Ali A, Shah Z, Muhammad SA. Biosynthesis, characterization, and biological activities of iron nanoparticles using Sesamum indicum seeds Extract. Pharmacognosy Magazine. 2017;13(Suppl 1):S33-S36. doi:10.4103/0973-1296.203985

22. Khatami M, Pourseyedi S. Phoenix dactylifera (date palm) pit aqueous extract mediated novel route for synthesis high stable silver nanoparticles with high antifungal and antibacterial activity. IET Nanobiotechnology. 2015;9(4):184-190.

23. Thukkaram M, Sitaram S, Kannaiyan Sk, Subbiahdoss G. Antibacterial efficacy of iron-oxide nanoparticles against biofilms on different biomaterial surfaces. Int J Biomater. 
2014;2014:6. doi:10.1155/2014/716080

24. Masadeh MM, Karasneh GA, Al-Akhras MA, et al. Cerium oxide and iron oxide nanoparticles abolish the antibacterial activity of ciprofloxacin against gram positive and gram negative biofilm bacteria. Cytotechnology. 2015;67(3):427-435. doi:10.1007/s10616-014-9701-8

25. de Toledo LdAS, Rosseto HC, Bruschi ML. Iron oxide magnetic nanoparticles as antimicrobials for therapeutics. Pharm Dev Technol. 2017:1-8. doi:10.1080/10837450.201 7.1337793
26. Khalil AT, Ovais M, Ullah I, Ali M, Shinwari ZK, Maaza M. Biosynthesis of iron oxide (Fe2O3) nanoparticles via aqueous extracts of Sageretia thea (Osbeck.) and their pharmacognostic properties. Green Chemistry Letters and Reviews. 2017;10(4):186-201. doi: 10.1080/17518253.2017.1339831.

27. Seddighi NS, Salari S, Izadi AR. Evaluation of antifungal effect of iron-oxide nanoparticles against different Candida species. IET Nanobiotechnology 2017;11(7): 883-888. doi: 10.1049/iet-nbt.2017.0025. 